\title{
Probing Adaptive Farm-Based Decision-Making: Assessing Micro-Catchment Practices towards Smart Agricultural Intensification within Muooni Sub-Catchment, Kenya
}

\author{
Nkeepebo Yesutanbul Amos ${ }^{1}$, Luwesi C. Ngonzo ${ }^{2}$, Madyanga P. Juvenary ${ }^{3}$ \\ ${ }^{1}$ Friends of the Earth-Ghana, PMB, GPO, Accra, Ghana \\ ${ }^{2}$ CGIAR Research Program on Water, Land and Ecosystem (WLE), International Water Management Institute (IWMI) - West Africa Office \\ CSIR Campus, Martin Odei Block, Airport Residential Area, PMB CT 112, Cantonments, Accra \\ ${ }^{3}$ Dar es Salaam University (DUCE campus), Dar Es Salaam, PO. BOX 2329, Tanzania. +255786923848
}

\begin{abstract}
Riparian areas provide many critical ecosystem functions, including reducing nutrients and sediments from surface runoff, reducing erosion, and providing shade and organic matter to stream ecosystems. The Muoonimicro-catchment area is densely settled and degraded as a result of land sub-divisions arising from the ever increasing population. Land fragmentation is very common in the area and therefore, conserving the riparian vegetation is important in the management of the Muooni dam as a source of water for a multiplicity of uses. In this paper we examined the conservation practices of the riparian vegetation in the Muooni dam microcatchment with in-depth interviews, transect walks and field observation techniques and noted that diverse land use practices are seriously affecting the quality of the riparian vegetation and the quality of the dam by increasing sediment loading within the dam. There are pockets of effort by the local farmers in preventing soil erosion in their farms along Muooni dam. However, strengthening the connection between government initiatives and individual famer initiatives is more likely to have a greater outcome. It is therefore deemed imperative for the local authorities to initiate farmer group activities taking the set-up of innovation platforms to conserve the riparian land and vegetation.
\end{abstract}

\section{Background of the Study}

Riparian areas provide many critical ecosystem functions, including reducing nutrients and sediments from surface runoff, reducing erosion, and providing shade and organic matter to stream ecosystems (Jaetzold et al., 2007 and FAO, 2011). The destruction of riparian vegetation along rivers is increasingly leading to soil erosion on the slopes of microcatchments and sediment loading in river dams. Kenya among other developing countries is not an exception. Several rivers, streams and dams are affected by humaninduced drivers and have resulted into sediment loading. The study carried out by (Jaetzold et al., 2007) in Eastern Kenya, shows that land-use practices are increasing every day, and soil erosion is becoming the associated problem. At the Muooni dam -catchment in Machakhos County-Kenya, conservation of the riparian vegetation has been given relatively less attention. As such, the riparian vegetation is highly disturbed through cattle grazing, bush fires upstream, tree cutting for timber production, sand harvesting in the downstream of the dam, poor agricultural practices (clearing and bush fires for farm preparations), cutting of the virgin vegetation as animal fodder in the catchment. This has become threatening story in water resources sustainability and calling for the building of local adaptation models as a means of informing forward-thinking decision making regarding watershed sustainability in Kenya.The IPCC AR5 is quite certain that differences in vulnerability and exposure arise from non-climatic factors. However, the response to vulnerability and exposure is differentiated by multidimensional inequalities often produced by uneven development processes. These differences shape differential risks from climate change. People who are socially, economically, culturally, politically, institutionally, or otherwise marginalized are especially vulnerable to climate change and also to some adaptation and mitigation responses (IPCC, 2007;FAO, 2011; IPCC, 2014). Therefore, vulnerability assessments require that researchers begin with an assessment of current exposures, sensitivities and current adaptive capacity, employing ethnographic in-community methods (including such tools as farm-based observation and focus groups), as well as insights from local and regional decision-makers, resource managers, scientists, published and unpublished literature, and other available sources of information. The aim of such analysis is to identify and document the conditions or risks (current and past exposures and sensitivities) that people have to deal with, and how they deal with these, including the factors and processes that constrain their choices (current and past adaptive capacity) (Pettengell, 2010). Studies suggest that there are multiple scopes and timings for adaptive interventions (for example, Smit et al., 2000; UN-Habitat, 2005; Smit and Wandel, 2006; UNFCCC, 2007; Silva Villanueva, 2011). Adaptive capacity assessment helps determine the capacity of human systems in order to identify and address weaknesses in planning initiatives, examine development initiatives through a climate change lens or as a component of climate vulnerability assessment (described separately as a different but related approach).The Local Adaptive Capacity (LAC) framework developed by the African Climate Change Resilience Alliance (ACCRA) makes clear that on a local level, rather than looking at what a community has, LAC analyses what the community does and how it does it. These are important technical 


\section{International Journal of Science and Research (IJSR) \\ ISSN (Online): 2319-7064}

Index Copernicus Value (2013): 6.14 | Impact Factor (2014): 5.611

considerations for local adaptation but more emphasis is needed on the local innovations and choices that are made through the selection of adaptation pathways. In this paper, we examine the local adaptation pathways and associated innovations leading to resilience (maintaining the status quo), transition (incremental change) and transformation (radical change) around the Muooni sub-catchment in Kenya. Whereas there are numerous approaches to addressing this issue, local innovation capacity is central to the adaptation discourse and every form of watershed action. We provide a firsthand attempt to answering the following questions within the LAC framework:

1) What is the nature of riparian vegetation changes in the Muooni sub-catchment?

2) How are farm-based innovations around the Muooni subcatchment that contributing to resilience (maintaining the status quo), transition (incremental change) and transformation (radical change) around the Muooni subcatchment?

3) How responsive are the changing community dynamics in support of local adaptive capacities around the Muooni sub-catchment?

\section{Study Materials and Methods}

Mixed methods were used in collection of data. Mixed methods approach offered an opportunity to draw from the strengths of both quantitative and qualitative research approaches (Johnson \& Onwuegbuzie, 2004). First, the study reviewed second-hand data from published and unpublished materials to provide a supporting theoretical framework for guiding the analysis and discussion. The secondary sources included journals, scientific reports, dissertations, websites, and other relevant sources of material information relevant riparian vegetation cover, conservation practices along the Muooni catchment. Primary quantitative data was collected using questionnaires coupled with on-farm observations. Quantitative data was collected through expert knowledge on the local dynamics of the Muooni sub-catchment and appropriate adaptive capacity models. It also made use of open, creative conversations and in-depth interviews as well as focused on challenges and opportunities facing and shaping farmer"s decisions with regard to water conservation within the sub-catchment. A number of school of thought influence the choice of variables in adoption and adaptation studies contained inactor oriented(Long, 1992; Mwaseba et al., 2006); economic constraint (Adesina \& Zinnah, 1993 and Agresti, 2007); innovation, and diffusion (Rogers, 2003). A binary logistic regression was however adapted to determine factors influencing water conservation specified as:

$\operatorname{Logit}(\mathrm{P}(\mathrm{y}=1))=\log (\mathrm{P} /(1-\mathrm{P}))=\alpha+\beta 1 \mathrm{X} 1+\beta 2 \mathrm{X} 2+\ldots+$

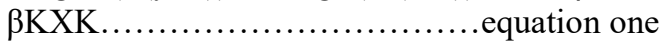

Where;

$\mathrm{Y}$ is a categorical response variable with $1=$ adopters and $0=$ otherwise;

$\alpha$ is the intercept;

$\beta 1, \beta 2 \ldots . \beta \mathrm{k}$ are coefficients of independent variables $\mathrm{X} 1$ $\mathrm{X} 2 \ldots \mathrm{XK}$;
$\mathrm{P}$ is the probability of adopting water conservation innovation and

(1-P) is the probability that a farmer does not adopt water conservation innovation.

The study leans on aprimary factor analysis using radar chart to provide additional information in identifying factors influencing the extent of innovation in terms of area. This model was also suitable because it made it easy to investigate relationships between a continuous response variable (Area) and some explanatory variables some being continuous and others categorical (MINITAB, 2010). The analysis also place premium on in-depth understanding of the local adaptive capacity of the micro-catchment. Qualitative analysis of information was a continuous process starting during data collection on identified major themes and ending with an in-depth description of the results. In other words exploratory thematic and content analysis (Johnson \& Onwuegbuzie, 2004) was used for this study. Direct quotations of key expressions were also used but the names and places of respondents were not disclosed due to ethical reasons.

\section{Results and Discussions}

\subsection{Land-Water Use Profile}

The Muooni sub-catchment area comprises several land-use activities mainly agricultural in nature such as cash crop farming mainly coffee, food crop farming, animal keeping and tree planting (Eucalyptus, Grevillea, Pine, Cyprus and Fruit trees). Other non-agricultural land-use activities identified were sand mining, water harvesting and brick making. The sub-catchment is a steep sloped area with an average slope angle of 46 degrees (run divide by rise angle), the land-use activities practiced expose the soils to high degree of degradation through soil erosion despite the various measures the community engages in, to control and contain it. The Muooni dam is the main source of piped water in the entire sub-catchment. It supplies water to institutions (schools, hospitals, markets) and farmerhouseholds. The dam was constructed in 1986 with a capacity of $836 \mathrm{~m} 3$, targeting to supply 30,000 people with water within and outside the sub-catchment area (Machakos District Draft Report, 2008). The sub-catchment is densely settled and degraded as a result of land sub-divisions arising from the ever increasing population. Land fragmentation was very common in the area as evident and confirmed during the study. This has been attributed to young men marrying and moving away from their parent's homesteads and settling on their inherited farming land curved from the family land. The land fragmentation has reduced land productivity where a good agricultural land is converted into settlement and other non-productive land-use activities.

\subsection{Smallholder Intensification and Wateruse in Muooni Dam}

During the study, it was identified that there were plans to put up check dams upstream during the dam construction period to prevent and control siltation and sediment transport but this was never done. Its capacity has reduced drastically to less than $450 \mathrm{~m} 3$ due to siltation, caused by 


\section{International Journal of Science and Research (IJSR) \\ ISSN (Online): 2319-7064}

Index Copernicus Value (2013): 6.14 | Impact Factor (2014): 5.611

poor land-use practices upstream which lead to soil erosion and transportation of sediments into the dam. The largest proportion of threatening factors in the Muooni dam are human induced factors particularly, agriculture, pastoralism, sand mining, tree and grass cutting. Before the construction of the dam in 1985 , water supply to the area was obtained from an underground spring at Kathaiyoni about $1 / 2 \mathrm{~km}$ upstream of the dam which was yielding high volumes of water and distributed by gravity flow, but due to encroachment by farming activities and planting of eucalyptus trees, this source has dried up and only yields water during the rainy season. Observations during the study is that because the dam is not fenced, people move their animals to graze around and drink water direct from the dam exposing it to contamination and pollution from animal droppings and especially donkeys. The riparian vegetation is used by farmers for feeding the livestock and some of the individuals in the family are engaging into grass cutting and sell it to other pastoralists. Even though some of the farmers do practice zero grazing but overgrazing downstream is still going on. This is seriously affecting the riparian vegetation in the catchment where large heads of livestock do graze very close to the river and dam. Farmers living near water sources are exposing the water sources to degradation, as evident from cultivation along river banks on streams and especially growing of vegetables; farming activities on steep slopes; planting of eucalyptus trees on streams, river banks and water points; intense sand harvesting stretching into the dam area causing sedimentation and siltation of water sources. Deforestation was also a common habit for the community around the catchment where they do cut trees for various purposes such as for house building and timber production.
There are different sources of water for the agricultural activities in the sub-catchment. Direct rainfall, water from Muooni dam, streams, springs and shallow wells were identified as the main sources of water for different land-use activities with direct rainfall being the main water source for farming activities in the sub-catchment. Out of the 25 respondents, $63.6 \%$ respondents indicated that they depended on rainfall as their main source of water for the different land-use activities followed by streams, while dams and piped water was rated as the least sources of water. This could be attributed to the land sizes in the area that are so small to allow for excavation and construction of community dams, and also the terrain of the area that cannot allow use of heavy machinery.

Table 1: Land size Rain fed crop farming Rain fed crop farming

\begin{tabular}{|c|c|c|}
\hline Farm Size & Rainfed & Non Rainfed \\
\hline Less than 1 acre & 5 & 0 \\
\hline 1-2 acres & 10 & 2 \\
\hline $2-3$ acres & 2 & 2 \\
\hline 3-4 acres & 1 & 0 \\
\hline 4 acres plus & 2 & 1 \\
\hline Total & $\mathbf{2 0}$ & $\mathbf{5}$ \\
\hline
\end{tabular}

Source: Authors (2014)

Within the micro-catchment of the Muooni dam, irrigated crop farming is mostly practiced by farmer-households less than 20 metres from water source as compared to farmerhouseholds settled more than 20 metres from the water source. This is mainly due to the easy access to water for irrigated crop farming from the dam. The farmers living outside the 20 metres proximity incurred high costs of transporting the water to their farms by use of pipes or digging canals (see figures $1.2 \& 1.3$ ).

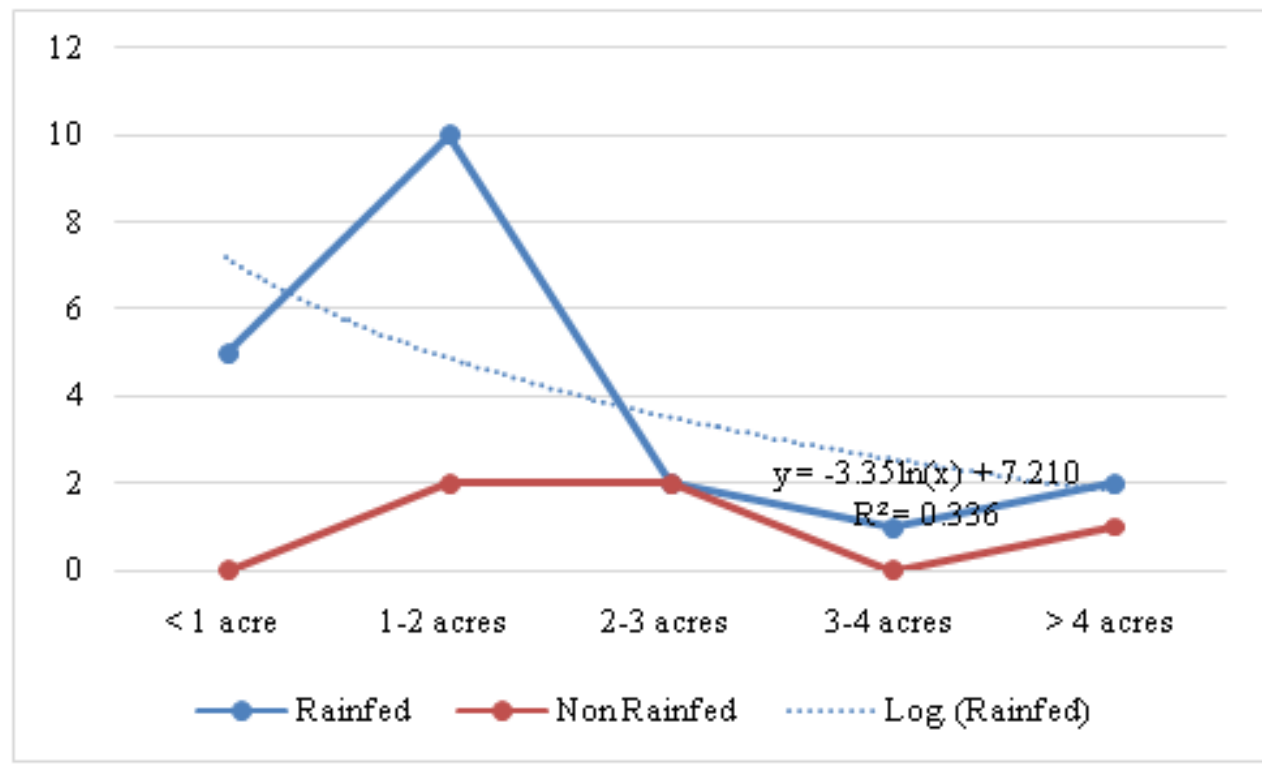

Figure 1.2: A binary logistic regression of water source by size of farmlands in Muooni Source: Authors (2014) 


\section{International Journal of Science and Research (IJSR) \\ ISSN (Online): 2319-7064}

Index Copernicus Value (2013): 6.14 | Impact Factor (2014): 5.611

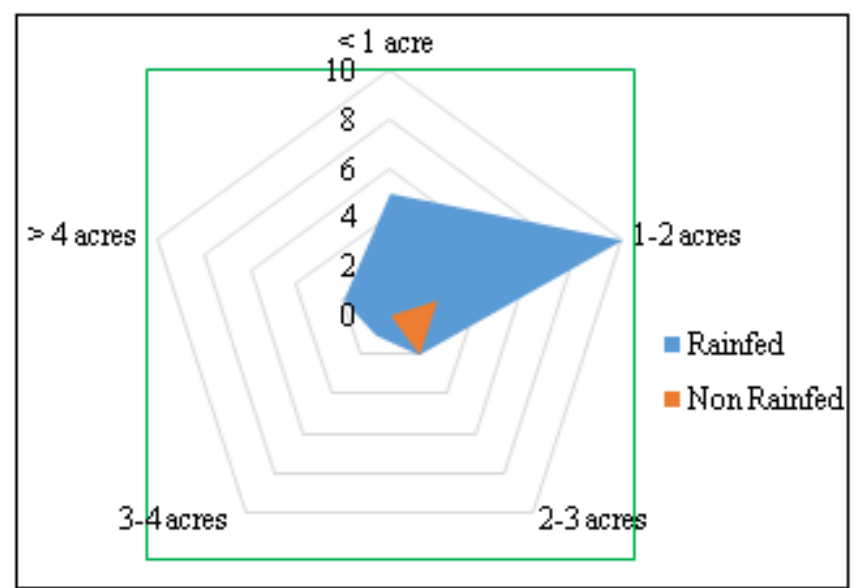

Figure 1.3: Radar chart of the distribution of water source by size of farmlands in Muooni

Source: Authors (2014)

\subsection{Farmer-based Innovations and Climate Smart Options}

The topography of the Muooni catchment is of undulating slopping land that can easily eroded by running water. Cultivation on the slopping land has necessitated the use of terracing to avoid the removal of the crops and top soil through runoff wash downstream into the dam. One among the interviewed farmers said; "...the use offarming through terracing is the local initiatives and not order from the government....During elinino in 1990's there was heavy rainfall where farms and crops were washed down into the dam, people decided to strengthen their farming through use of terracing" (local farmer in the catchment 2014). There are several of terrace farmlands a few meters surrounding the dam. Through the use of terracing, the farmers reduce the rate of erosion and indirectly conserve the riparian land though their objective is to prevent soil erosion in their farms. Farmers in the sub-catchment have been actively engaged in the establishment of woodlots using agroforestry approaches. There are various tree species grown in the area, the most predominant being the blue gum tree, an exotic species of the eucalyptus tree. In the Muooni catchment, farmers are committing to the use of coffee trees as a means of controlling erosion on their farms. From the ground observations, it was noticed that most of the farmers are mixing commercial crops with other food crops, particularly on steep slopes along the edge of the dam. The trees in the farms create a layer of soil stability and reduce erosion. Other species are grevillea, pine, cyprus and fruit trees. The indigenous species of the eucalyptus tree has been replaced gradually with a new species of eucalyptus introduced in the area in 1999 from South Africa. According to information from the divisional forestry officer and the community, the introduction of the species from South Africa was made to re-afforestate the higher parts of the subcatchment which had been deforestated, but the planting of these trees spread to the low parts of the sub-catchment due to its quick maturity period. There are various types of tree species such as eucalyptus and horticulture which is practiced as agro-forestry.

There has been an increasing awareness on the negative effects of these tree species on water sources. Various initiatives such as the introduction of alternative species mainly grevillea and fruit trees are being put in place by the Government and an NGOs known as BIDI (Benevolent Institute of Development Initiatives) operating in the subcatchment to try address this problem and remove these "unfriendly environmental trees" from the sub-catchment. The community has been encouraged by the Provisional Administration and a Non-governmental organization operating in the sub-catchment to voluntarily cut and replaced the existing eucalyptus trees and especially those at or near water sources such as the Muooni dam. In the Muooni catchment some of the farmers have been doing zero grazing where cattle are closed into their bomas and fed with cut grasses. This is good method of reducing exploitation of the riparian vegetation. The farmers are keeping few number of livestock. Not all farmers do practices zero grazing some of the farmers are seriously affecting the riparian vegetation by using it as grazing land and it was also observed that even those who are practicing zero grazing were still depending on the riparian grasses for feeding their cattle at home. One other conservation method that is best practiced in the Muooni catchment is growing of grasses on the slopping land of the catchment. Farmers have grown grasses in the catchment so as to prevent soil erosion by runoff. The downstream riparian areas is green by grasses which sometimes are used as animal fodder.

The IPCC defines adaptive capacity as the ability of a system to adjust to climate change (including climate variability and extremes) to moderate potential damages, to take advantage of opportunities, or to cope with the consequences (IPCC 2014). Adaptation in developing countries has attracted a great deal of attention in recent years. This is due, in part, to our increasing understanding of humankind's influence on the climate system and the recognition that actions may be needed to help communities deal with the consequences. Addressing adaptation issues is a central part of the international climate change negotiations (UNFCCC, 2007). At the heart of any locallevel adaptation intervention is the need to increase the individual or community"s adaptive capacity (Brooks, 2003). A key component of this is ensuring that individuals, communities and societies are actively involved in processes of change (Pettengell, 2010). As discussed above, direct assessments of adaptive capacity are not feasible, and so it becomes necessary to identify the characteristics or features that influence it. The emphasis in our study is therefore on the local innovations in land use that are shaping the adaptive pathways and influencing adaptive capacity around the Muooni dam. As observed by Musuva in 2008, there are individual efforts taken by the local farmers in trying to prevent soil erosion in their farms which inadvertently contribute marginally to conservation. This efforts however, are not significant enough to trigger a transition or even improve resilience since they are differentiated over time and space and lacks any form of consolidation.

\section{Conclusion and Recommendations}

The current farming practices within the Muooni microcatchment area are threatening water resource sustainability and calling for the building of local adaptation models as a means of informing forward-looking decision-making regarding watershed sustainability in Kenya. Whereas there 


\section{International Journal of Science and Research (IJSR) \\ ISSN (Online): 2319-7064}

Index Copernicus Value (2013): 6.14 | Impact Factor (2014): 5.611

are numerous approaches to addressing this issue, influencing the adaptive capacity of local inhabitants through local innovations has become a crucial aspectin every form of watershed action as so is it in Muooni. Experimentation, innovation and adoption are influencing local resilience by ensuring the riparian land's ability to cope with and respond to changing circumstances. There are individual efforts taken by the local farmers in trying to prevent soil erosion in their farms along Muooni dam suggesting that government initiatives at enhancing local adaptive capacity fall short. Strengthening the connection between government initiatives and individual famer initiatives is more likely to have a greater outcome. It is therefore imperative for the local authorities to initiate farmer group activities to conserve the riparian land and vegetation. Again this will require a joint effort as opposed to individual or compartmentalized actions.

\section{References}

[1] ACCRA (2012). The ACCRA Local Adaptive Capacity framework,Consultation Document: The ACCRA Local Adaptive Capacity Framework (LAC).

[2] Adesina, A. A., \& Zinnah, M. M. (1993). Technology characteristics, farmers' perceptions and adoption decisions: A Tobit model application in Sierra Leone. Agricultural Economics, 9, 297-311.

[3] Agresti, A. (2007). An Introduction to Categorical Data Analysis (2 ed.). Hoboken, New Jersey: JohnWiley \&Sons, Inc. (Chapter 4). http://dx.doi.org/10.1002/0470114754

[4] FAO. (2011). Climatic Risk Analysis in Conservation Agriculture in Varied Biophysical and SocioeconomicSettings of Southern Africa, Network paper, 3. Rome: FAO.

[5] IPCC (2007). Climate Change 2007: Mitigation. Contribution of Working Group III to the Fourth 7 Assessment Report. Intergovernmental Panel on Climate Change.

[6] Long, N. (1992). From paradigm lost to paradigm regained? The case for an actor-oriented sociology of development. In N. Long \& A. Long (Eds.), Battlefields of Knowledge: The Interlocking of Theory andPractice in Social Research and Development (pp. 16-43). London: Routledge.

[7] IPCC, (2014): Summary for policymakers. In: Climate Change 2014: Impacts, Adaptation, and Vulnerability. Part A: Global and Sectoral Aspects. Contribution of Working Group II to the Fifth Assessment Report of the Intergovernmental Panel on Climate Change [Field, C.B., V.R. Barros, D.J. Dokken, K.J. Mach, M.D. Mastrandrea, T.E. Bilir, M. Chatterjee, K.L. Ebi, Y.O. Estrada, R.C. Genova, B. Girma, E.S. Kissel, A.N. Levy, S. MacCracken,P.R. Mastrandrea, and L.L. White (eds.)]. Cambridge University Press, Cambridge, United Kingdom and New York, NY, USA, pp. 1-32.

[8] Jaetzold, R., Schmidt, H., Hornet, Z.B. and Shisanya, C.A. 2007a. Farm Management Handbook of Kenya. Natural Conditions and Farm Information. 2nd Edition. Vol.11/ C. Eastern Province. Ministry of Agriculture/ GTZ, Nairobi, Kenya.

[9] Johnson, R. B., \& Onwuegbuzie, A. J. (2004). Mixed Methods Research: A research paradigm whose time has come. Educational researcher, 33(7), 14-26. http://dx.doi.org/10.3102/0013189X033007014

[10] Kenya Land Alliance (2007). Land Use in Kenya. The Case for a National Land Use Policy, Land Reform Volume 3. Printfast Kenya Limited, Nairobi, Kenya.

[11] Machakos District Draft Report, 2008, Short Rains Assessment, Machakos, Kenya.

[12] Mwaseba, D. L., Kaarhus, R., Johnsen, F. H., Mvena, Z. S. K., \& Mattee, A. Z. (2006). Beyond adoption/rejection of agricultural innovations: Empirical evidence from smallholder rice farmers inTanzania. Outlook on Agriculture, 35(4), 263-272. http://dx.doi.org/10.5367/000000006779398245

[13] Pettengell, C. (2010). Climate Change Adaptation: Enabling people living in poverty to adapt. Oxford: Oxfam GB (www.oxfam.org.uk/resources/policy/climate_change/d ownloads/rr_climate_change_adaptation_full_290410.p df).

[14] Rogers, E. M. (2003). Diffusion of Innovations (5th ed.). London: Free Press, (Chapter 1 and 5).

[15] Silva Villanueva, P. (2011). Learning to ADAPT: monitoring and evaluation approaches in climate change adaptation and disaster risk reduction - challenges, gaps and ways forward. SCR Discussion Paper 9.

[16] Smit, B. and Wandel, J. (2006). ,Adaptation, adaptive capacity and vulnerability"e, GlobalEnvironmental Change 16 (3): 282-292.

[17]UNFCCC (2007) Impacts, Vulnerabilities and Adaptation in Developing Countries. New York:United Nations Framework Convention on Climate Change(http://unfccc.int/resource/docs/publications/imp acts.pdf).

[18] UN-Habitat, 2005, A Guidebook For Local Catchment Management In Cities, Nairobi, Kenya 